Article Type: Clinical Article

\title{
Effect of body mass index on the incidence of perineal trauma
}

Constantin M. Durnea ${ }^{1, *}$, Ali E. Jaffery ${ }^{2}$, Nivedita Gauthaman ${ }^{3}$, Stergios K.

Doumouchtsis $^{1,2}$

${ }^{1}$ Department of Obstetrics and Gynaecology, Epsom and St Helier University Hospitals NHS Trust, Epsom, UK

2 St George's University of London, London, UK

${ }^{3}$ Department of Obstetrics and Gynaecology, Hampshire Hospitals NHS Foundation Trust, Basingstoke, UK

\section{${ }^{*}$ Correspondence}

Constantin M. Durnea, Department of Obstetrics and Gynaecology, Rowan House, Dorking Rd, Epsom KT18 7EG, UK.

Email: costea.durnea@gmail.com

This article has been accepted for publication and undergone full peer review but has not been through the copyediting, typesetting, pagination and proofreading process, which may lead to differences between this version and the Version of Record. Please cite this article as doi: 10.1002/ijgo.12403

This article is protected by copyright. All rights reserved. 
Keywords: Body mass index; Obesity; Obstetric anal sphincter injuries; Perineal tear; Risk factor; Vaginal delivery

Synopsis: Increased body mass index was associated with a reduced incidence of minor perineal trauma.

\begin{abstract}
Objective: To investigate the association between perineal trauma at childbirth and maternal body mass index (BMI), and estimate the risk of perineal trauma among different BMI groups.
\end{abstract}

Methods: Data were retrospectively assessed from all vaginal deliveries in a UK tertiary maternity unit between 1999 and 2014. Associations between BMI at booking and first- and second-degree tears (minor perineal trauma), third- and fourth-degree tears (obstetric anal sphincter injuries [OASIS]), and frequency of instrumental deliveries were assessed. Multivariate logistic regression included the factors BMI (weight in kilograms divided by the square of height in meters), age, ethnicity, smoking, parity, pregnancy length, episiotomies, instrumental delivery, and birth weight.

Results: Data from 45557 deliveries were used. Compared with women with a normal BMI (<25), odds of minor perineal trauma were significantly reduced among women with obesity (BMI 30 to $<35$; odds ratio [OR] $0.91,95 \%$ confidence interval [CI] $0.84-0.99$ ) or severe obesity (BMI $\geq 35$; OR $0.87,95 \% \mathrm{Cl} 0.77-0.98)$. OASIS 
was not significantly associated with BMI. Instrumental delivery rates were higher among women with normal BMI (5936/27 107, 22.0\%) than among those with severe obesity $(284 / 2032,14.0 \%)$.

Conclusion: Increased BMI at booking was associated with a reduced incidence of minor perineal trauma at delivery, but was not associated with OASIS.

\section{INTRODUCTION}

Obesity in women is defined as a body mass index (BMI, calculated as weight in kilograms divided by the square of height in meters) of at least 30 , or a body fat percentage of at least $30 \%$ [1]. In $2014,22 \%$ and $27 \%$ of all pregnant women in the UK were reported to be overweight and obese, respectively [2].

Obesity in pregnancy is associated with complications such as spontaneous abortion, thromboembolism, hypertensive disorders, gestational diabetes, and preterm delivery, among others [3]. Furthermore, obese women experience more complications during labor and delivery, including induction of labor, epidural failure, increased rates of cesarean delivery, and shoulder dystocia [4].

Vaginal delivery can result in perineal trauma; in the UK, $85 \%$ of women who deliver vaginally are reported to sustain some degree of perineal tear [5]. The main contributing factors are nulliparity, forceps delivery, longer duration of second stage of labor, and higher birth weight [6]. However, there are conflicting reports regarding the association between obesity and childbirth-related perineal trauma. Some 
studies have reported a lower risk of obstetric anal sphincter injuries (OASIS) with increasing BMI by comparison with women with a normal BMI (odds ratio [OR] 0.47, $95 \%$ confidence interval [CI] 0.28-0.78) $[7,8]$, whereas others have demonstrated a significant association between obesity and significant perineal trauma, whereby the probability of trauma is increased by $78 \%$ for obese women $[9,10]$. These discrepancies could reflect differences both in the study populations and in obstetric practice.

The primary aim of the present study was to investigate further the association between obesity and perineal trauma in a large single-center maternity department in the UK. A secondary aim was to determine the association between high BMI and instrumental delivery.

\section{MATERIALS AND METHODS}

The present retrospective observational cohort study assessed data from all women who delivered at St George's University Hospital, London, UK, between January 1, 1999, and December 31, 2014. The only exclusion criteria were delivery by cesarean and missing BMI information. The study was registered with the local audit department. Ethical approval and informed consent were not required because the study included data collected during standard practice and it was a retrospective audit (chart review) of all deliveries during the study period. 
Data on all deliveries were acquired from the electronic patient database. The primary outcome measures were the associations between BMI and perineal trauma at vaginal delivery, and BMI and rate of instrumental delivery. Outcomes were grouped as first-, second-, third-, and fourth-degree tears, and intact perineum with spontaneous vaginal delivery. The women were stratified into four categories on the basis of BMI: less than 25 (normal and underweight), 25 to less than 30 (overweight), 30 to less than 35 (obese), and higher than 35 (severely obese).

The secondary outcome measures were the associations between perineal lacerations and $\mathrm{BMI}$, age $(<20,21-25,26-30,31-35,36-40$, and $>40$ years $)$, ethnicity (white, black, Subcontinental Asian, Southeastern Asian, and other), smoking, parity (nulliparous and multiparous), pregnancy length, episiotomy, instrumental delivery, and birth weight (cutoff point $4 \mathrm{~kg}$ ); these variables have previously been associated with childbirth perineal trauma and might be confounders [9].

The data were analyzed using SPSS version 21 (IBM, Armonk, NY, USA). Multivariate logistic regression was performed to assess the associations between perineal trauma and BMI with normal weight used as the reference group. Perineal tears were grouped for these analyses into minor perineal trauma (first- and seconddegree tears), and OASIS (third- and fourth-degree tears). All secondary outcome variables were included in the final model. $P<0.05$ was considered statistically significant. 


\section{RESULTS}

Among 67278 women who delivered during the study period, 21721 (32.0\%) were excluded, including 13004 (19.3\%) who delivered by cesarean and 8717 (12.9\%) who had missing information regarding BMI or perineal tears. Thus, data from 45557 deliveries were analyzed.

Among the study population, the most common ethnic background was white $(\mathrm{n}=24071,52.3 \%)$, followed by black $(\mathrm{n}=7332,17.3 \%)$, Subcontinental Asian $(n=6691,15.1 \%)$, Southeastern Asian $(n=2402,5.6 \%)$ and other $(n=5061,7.5 \%)$.

The median age was similar in all BMI groups (Table 1). The highest BMI was observed among black women, followed by Subcontinental Asian women (Table 1). Overall, first- and second-degree perineal tears were the most common outcomes of vaginal delivery (Table 2).

The frequency of instrumental deliveries decreased with increasing BMI (Figure 1). Patients with a BMI of less than 25 had the highest rate of instrumental deliveries $(5963 / 27107,22.0 \%)$ and severely obese women had the lowest rate $(284 / 2032$, 14.0\%) (Figure 1).

Multivariate analysis was performed to identify factors associated with minor tears (Table 3) and OASIS (Table 4). For both types of injury, increasing BMI was inversely associated with risk; however, the association was not significant for OASIS. As compared with the reference group of white women, black women had a 
lower risk of OASIS $(P<0.001)$, and Southeastern Asians had the highest risk $(P<0.001)$. Instrumental delivery was the most significant risk factor for OASIS $(P<0.001)$. Smoking decreased the risk of perineal trauma, whereas primiparity, pregnancy length, and birth weight increased it (all $P<0.001$ ).

\section{DISCUSSION}

The present study found that $73 \%$ of women experienced some form of perineal trauma, in keeping with previous reports [5]. Our OASIS rate of 3.5\% also is within the range reported previously [11]. The risk of both minor and major perineal lacerations was lower for obese women; however, the "protective" effect of obesity was not statistically significant for the latter category (i.e. OASIS). This is in line with previous reports, including studies in Sweden and the USA $[7,12]$. The common finding among the studies is that higher BMI is protective for perineal trauma. In the Swedish study, however, the risk of minor perineal trauma was positively associated, whereas OASIS was negatively associated, with increasing BMI [7]. The authors suggested that, because it was a nationwide study, the possibly highly significant results might be attributed to the large sample size rather than to large effect sizes.

The study in the USA demonstrated an inverse relationship between increasing BMI and OASIS, but the association was significant only among primiparous women and not among multiparous women [12].

Similar results were reported in another Swedish study of only primiparous women [8]; thus, parity seems to play a part in these associations. As compared with multiparous women, primiparous women are reported to have a 7.2-fold higher risk of OASIS during vaginal delivery [12]. This is in line with the present study, which 
found an OR of 8.6 for primiparous women. The differences in the studies might possibly reflect variations in obstetric practice. For example, episiotomy, which has been shown to slightly increase the risk of OASIS [13], has a rate of $6 \%$ among nulliparous and 1\% among multiparous women in Sweden [14], whereas the rate of episiotomy in the present study (18\%) is in agreement with average findings in the UK (15\%) [15].

By contrast with a previous report [16], the rate of instrumental deliveries was lower among women with high BMI in the present study. However, another study has also shown that these women might have a lower rate of instrumental deliveries [17]. This finding might be explained by the fact that some obese women have low gestational weight gain and benefit from a significantly reduced risk of instrumental delivery [18].

There is no consensus so far on the reasons for the lower incidence of perineal trauma among obese women. Some have argued that metabolic changes in these women can lead to decreased myometrial contractility, caused by reduced calcium flow or increased cholesterol levels in myometrial tissue [19], and thus to less precipitous labor.

The "protective" effect of obesity might be due to the mechanical properties of the perineum in obese women; however, it has been suggested that skin strength is generally weaker among these women. An association has been demonstrated between high BMI in pregnancy and the presence of striae gravidarum [20], which in 
turn is associated with collagen abnormalities leading to skin laxity [21] and weaker mechanical properties [22]. This could translate into a clinical association between striae gravidarum and perineal tearing [23]. The protective effect of obesity might also be due to a thicker subcutaneous fat layer. However, further biomechanical research is needed in this area.

Similar to a previous study [24], black women were less likely to sustain perineal tears compared with Southeastern Asian women in the present study. Also in line with a previous report [25], smoking seemed to have a protective effect against perineal tears. Despite this negative association, smoking in pregnancy should be strongly discouraged owing to morbidities such as birth defects and intrauterine growth restriction. Future research should explore in more detail the role of parity, low gestational weight gain, and biomechanical properties of tissue in obese pregnant women.

The strength of the study is the large sample size covering a long period. Additionally, the analysis assessed several confounding variables that are known to affect the risk of perineal trauma. Another strength involves the quality of the data collected. Data were collected from one institution, which reduces the risk of bias caused by differences in data collection or practices. In cases of OASIS, the Risk Management Team crosschecked data entries in patient's medical and electronic notes, thereby ensuring their accuracy. Last, the data included an ethnically heterogeneous population. 
The present study has some limitations. First, as a retrospective chart review, the data might have been subject to reporting or coding errors. The accuracy of the data was dependent on the entry made by the individuals who input them, and the data were not cross-verified from the medical records except for the cases of third- and fourth-degree tears. Although the effect of confounders was reduced by performing multivariable logistic regression analysis, there remained the risk that some potential confounders were not considered. Last, a considerable amount of data were incomplete, particularly for BMI, leading to the exclusion of 8717 (13.0\%) women from the study cohort.

In conclusion, the negative association between increasing BMI and perineal trauma has shown that obesity in pregnancy is not universally associated with adverse events. The rate of instrumental deliveries also seemed to be lower for obese women. The risk of childbirth-related perineal trauma was associated with primiparity, increasing pregnancy length and birth weight, and instrumental delivery. Black ethnicity and smoking reduced the risk of OASIS. Basic and translational research could shed light on pathophysiological mechanisms and changes in collagen status or other tissue effects, which might explain the observations in the present study and others.

\section{Author contributions}

CMD contributed to data analysis, and manuscript writing and revision. AEJ contributed to data management, data analysis, and manuscript writing and revision. NG contributed to data collection, and manuscript writing and revision. SKD contributed to project development, data collection, data analysis, and manuscript revision. 


\section{Conflicts of interest}

The authors have no conflicts of interest.

\section{References}

1. Frankenfield DC, Rowe WA, Cooney RN, Smith JS, Becker D. Limits of body mass index to detect obesity and predict body composition. Nutrition, 2001. 17(1): $p$. 26-30.

2. MBRRACE-UK. Lessons learned to inform future maternity care from the UK and Ireland Confidential Enquiries into Maternal Deaths and Morbidity 2009-2012. https://www.npeu.ox.ac.uk/downloads/files/mbrraceuk/reports/Saving\%20Lives\%20Improving\%20Mothers\%20Care\%20report\%202014 \%20Full.pdf. Published December 2014. Accessed November 10, 2017.

3. Sirimi, N. and D.G. Goulis, Obesity in pregnancy. Hormones (Athens), 2010. 9(4): p. 299-306.

4. Sebire NJ, Jolly M, Harris JP, et al. Maternal obesity and pregnancy outcome: a study of 287,213 pregnancies in London. Int J Obes Relat Metab Disord, 2001. 25(8): p. 1175-82.

5. Kettle, C. and S. Tohill, Perineal care. BMJ Clin Evid, 2008. 2008.

6. Smith LA, Price N, Simonite V, Burns E. Incidence of and risk factors for perineal trauma: a prospective observational study. BMC Pregnancy Childbirth, 2013. 13: p. 59. 
7. Lindholm, E.S. and D. Altman, Risk of obstetric anal sphincter lacerations among obese women. BJOG, 2013. 120(9): p. 1110-5.

8. Blomberg, M., Maternal body mass index and risk of obstetric anal sphincter injury. Biomed Res Int, 2014. 2014: p. 395803.

9. Meister MR, Cahill AG, Conner SN, Woolfolk CL, Lowder JL. Predicting obstetric anal sphincter injuries in a modern obstetric population. Am J Obstet Gynecol, 2016. 215(3): p. 310 e1-7.

10. D. Starič, D, Bukovec P, Jakopič K, Zdravevski E, Trajkovik V, Lukanović A. Can we predict obstetric anal sphincter injury? Eur J Obstet Gynecol Reprod Biol, 2017. 210: p. 196-200.

11. Blondel B, Alexander S, Bjarnadóttir RI, et al. Variations in rates of severe perineal tears and episiotomies in 20 European countries: a study based on routine national data in Euro-Peristat Project. Acta Obstet Gynecol Scand, 2016. 95(7): p. 746-54.

12. Landy HJ, Laughon SK, Bailit JL, et al. Characteristics associated with severe perineal and cervical lacerations during vaginal delivery. Obstet Gynecol, 2011. 117(3): p. 627-35.

13. Macleod M, Strachan B, Bahl R, et al. A prospective cohort study of maternal and neonatal morbidity in relation to use of episiotomy at operative vaginal delivery. BJOG, 2008. 115(13): p. 1688-94.

14. Rockner, G. and A. Fianu-Jonasson, Changed pattern in the use of episiotomy in Sweden. Br J Obstet Gynaecol, 1999. 106(2): p. 95-101. 
15. National Health Service. Maternity Statistics - England 2010-2011. https://digital.nhs.uk/catalogue/PUB03071. Published December 1, 2011. Accessed November 10, 2017.

16. Marchi J, Berg M, Dencker A, Olander EK, Begley C. et al. Risks associated with obesity in pregnancy, for the mother and baby: a systematic review of reviews. Obes Rev, 2015. 16(8): p. 621-38.

17. Janga, D., M. Parisaei, and K. Erskine, Revisiting instrumental vaginal delivery rates in obese pregnant women. Archives of Disease in Childhood - Fetal and Neonatal Edition, 2011. 96(Suppl 1): p. Fa88-Fa88.

18. Cedergren M. Effects of gestational weight gain and body mass index on obstetric outcome in Sweden. Int J Gynecol Obstet 2006; 93(3): 269-74.

19. Jie Zhang, Kendrick A, Quenby S, Wray S. Contractility and calcium signaling of human myometrium are profoundly affected by cholesterol manipulation: implications for labor? Reprod Sci, 2007. 14(5): p. 456-66.

20. Thomas, R.G. and W.A. Liston, Clinical associations of striae gravidarum. J Obstet Gynaecol, 2004. 24(3): p. 270-1.

21. Wang F, Calderone K, Smith NR et al. Marked disruption and aberrant regulation of elastic fibres in early striae gravidarum. Br J Dermatol, 2015. 173(6): p. 1420-30.

22. Enser, M. and N.C. Avery, Mechanical and chemical properties of the skin and its collagen from lean and obese-hyperglycaemic (ob/ob) mice. Diabetologia, 1984. 27(1): p. 44-9. 
23. Halperin O, Raz I, Ben-Gal L, Or-Chen K, Granot M. Prediction of perineal trauma during childbirth by assessment of striae gravidarum score. J Obstet Gynecol Neonatal Nurs, 2010. 39(3): p. 292-7.

24. Ogunyemi D, Manigat B, Marquis J, Bazargan M. Demographic variations and clinical associations of episiotomy and severe perineal lacerations in vaginal delivery. J Natl Med Assoc, 2006. 98(11): p. 1874-81.

25. McPherson KC, Beggs AD, Sultan AH, Thakar R. Can the risk of obstetric anal sphincter injuries (OASls) be predicted using a risk-scoring system? BMC Res Notes, 2014. 7: p. 471.

Figure legend

Figure 1 Frequency of instrumental delivery according to body mass index (calculated as weight in kilograms divided by the square of height in meters). 
Table 1 Age and ethnicity among the BMI groups. ${ }^{a}$

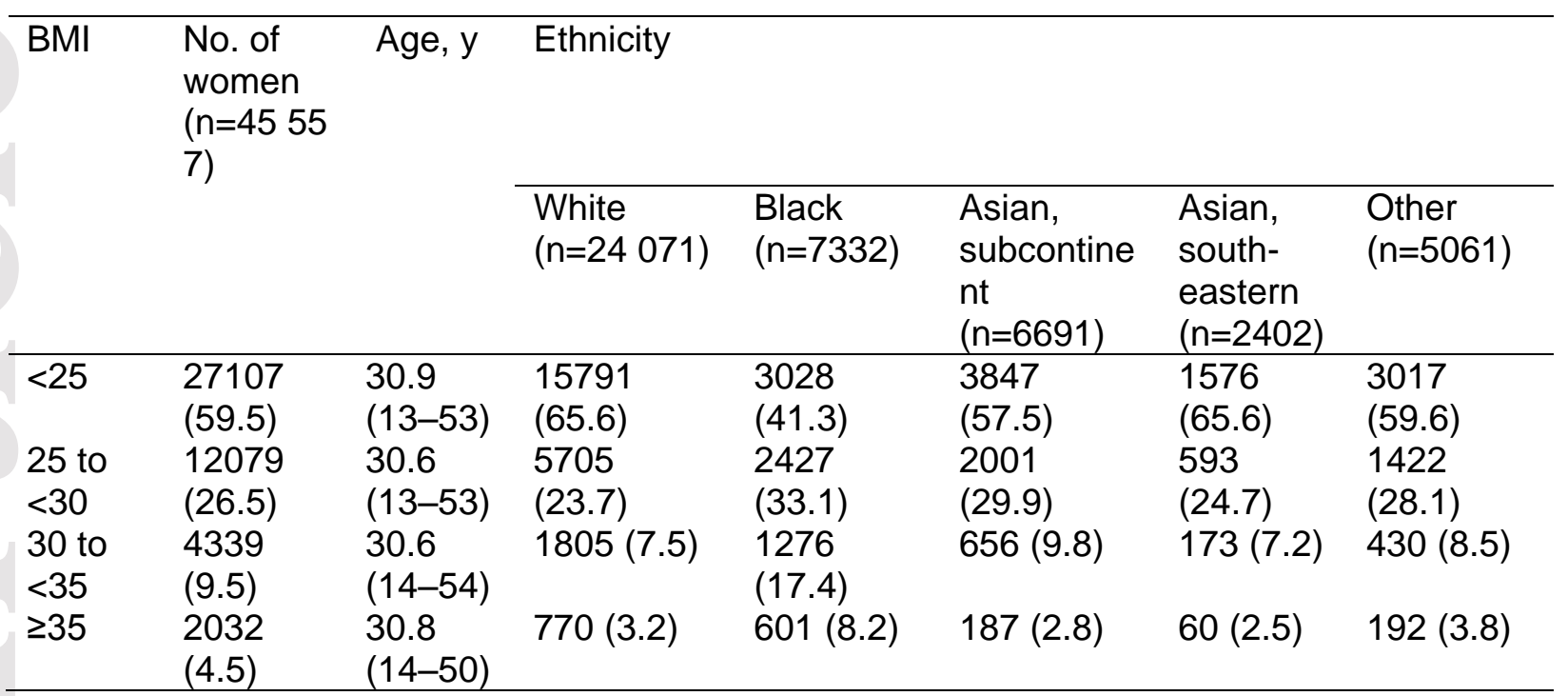

Abbreviation: BMI, body mass index (calculated as weight in kilograms divided by the square of height in meters).

a Values are given as number (percentage) or median (range).

Table 2 Frequency of perineal trauma in the study population $(n=45557)$.

\begin{tabular}{|l|l|}
\hline Perineal trauma & No. (\%) \\
\hline Intact perineum & $12064(26.5)$ \\
\hline 1st/2nd degree tear & $23523(51.6)$ \\
\hline 3rd/4th degree tear & $1615(3.5)$ \\
\hline Episiotomy & $8355(18.3)$ \\
\hline
\end{tabular}

This article is protected by copyright. All rights reserved. 
Table 3 Risk factors associated with first- and second-grade perineal tears by multivariate logistic regression.

\begin{tabular}{|c|c|c|}
\hline Factor & Odds ratio (95\% confidence interval) & $P$ value \\
\hline \multicolumn{3}{|l|}{ BMI } \\
\hline$<25$ & 1 & - \\
\hline 25 to $<30$ & $1.04(0.98-1.11)$ & 0.163 \\
\hline 30 to $<35$ & $0.91(0.84-0.99)$ & 0.03 \\
\hline$\geq 35$ & $0.87(0.77-0.98)$ & 0.02 \\
\hline Non-smoker & $3.90(2.89-5.29)$ & $<0.001$ \\
\hline \multicolumn{3}{|l|}{ Age, y } \\
\hline$\leq 20$ & 1 & - \\
\hline $21-25$ & $1.01(0.90-1.13)$ & 0.852 \\
\hline $26-30$ & $0.97(0.87-1.08)$ & 0.589 \\
\hline $31-35$ & $1.00(0.90-1.11)$ & 0.953 \\
\hline $36-40$ & $0.98(0.87-1.10)$ & 0.718 \\
\hline$>40$ & $1.08(0.88-1.32)$ & 0.48 \\
\hline \multicolumn{3}{|l|}{ Ethnicity } \\
\hline White & 1 & - \\
\hline Black & $0.47(0.44-0.50)$ & $<0.001$ \\
\hline $\begin{array}{c}\text { Asian } \\
\text { (Subcontinental) }\end{array}$ & $1.18(1.08-1.26)$ & $<0.001$ \\
\hline $\begin{array}{c}\text { Asian } \\
\text { (Southeastern) }\end{array}$ & $1.39(1.23-1.57)$ & $<0.001$ \\
\hline Other & $0.74(0.67-0.81)$ & $<0.001$ \\
\hline Primiparous & $2.63(2.49-2.78)$ & $<0.001$ \\
\hline Pregnancy length & $3.20(2.90-3.53)$ & $<0.001$ \\
\hline Instrumental delivery & 2.57 (2.26-2.93) & $<0.001$ \\
\hline Birth weight $<4$ kg & $0.47(0.36-0.62)$ & $<0.001$ \\
\hline
\end{tabular}

Abbreviation: BMI, body mass index (calculated as weight in kilograms divided by the square of height in meters).

This article is protected by copyright. All rights reserved. 
Table 4 Risk factors associated with third- and fourth-grade perineal tears by multivariate logistic regression.

\begin{tabular}{|l|l|l|}
\hline Factor & Odds ratio (95\% confidence interval) & $\boldsymbol{P}$ value \\
\hline BMI & & \\
\hline$<25$ & 1 & - \\
\hline 25 to $\leq 30$ & $1.14(0.99-1.30)$ & 0.058 \\
\hline 30 to $<35$ & $0.89(0.71-1.10)$ & 0.275 \\
\hline$\geq 35$ & $0.88(0.63-1.23)$ & 0.446 \\
\hline Non-smoker & $2.28(2.09-2.48)$ & $<0.001$ \\
\hline Age & & \\
\hline$\leq 20$ & 1 & - \\
\hline $21-25$ & $0.95(0.73-1.23)$ & 0.693 \\
\hline $26-30$ & $0.93(0.73-1.19)$ & 0.57 \\
\hline $31-35$ & $0.95(0.75-1.21)$ & 0.69 \\
\hline $36-40$ & $1.1(0.85-1.43)$ & 0.473 \\
\hline$>40$ & $1.15(0.74-1.8)$ & 0.527 \\
\hline Ethnicity & & - \\
\hline White & 1 & $<0.001$ \\
\hline Black & $0.39(0.32-0.48)$ & $<0.001$ \\
\hline $\begin{array}{l}\text { Asian } \\
\text { (Subcontinental) }\end{array}$ & $2.08(1.78-2.43)$ & $<0.001$ \\
\hline $\begin{array}{l}\text { Asian } \\
\text { (Southeastern) }\end{array}$ & $2.97(2.39-3.69)$ & $<0.001$ \\
\hline Other & $0.82(0.74-0.89)$ & $<0.001$ \\
\hline Primiparity & $8.60(7.46-9.83)$ & $<0.001$ \\
\hline Pregnancy length & $10.90(6.97-16.92)$ & $<001$ \\
\hline Instrumental delivery & $13.90(11.83-16.43)$ & \\
\hline Birth weight $<4$ kg & $0.12(0.08-0.18)$ & \\
\hline
\end{tabular}

Abbreviation: BMI, body mass index (calculated as weight in kilograms divided by the square of height in meters). 


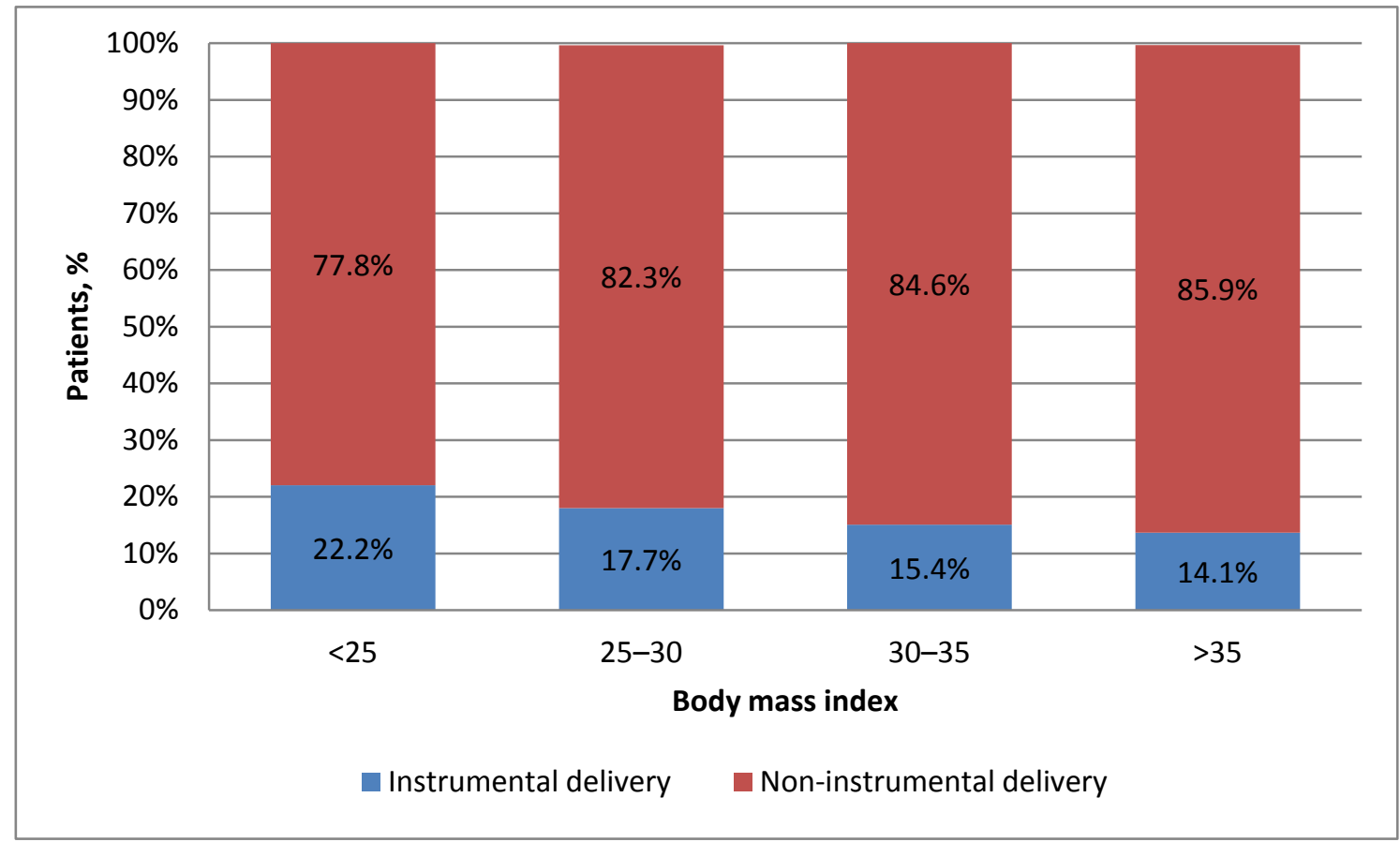

This article is protected by copyright. All rights reserved. 